\title{
The Current Situation and Prospect of Agricultural Cooperation between China and Timor-Leste
}

\author{
Huiping Liu \\ International Business School \\ Yunnan University of Finance and Economics \\ Kunming, China \\ hp953364780@126.com
}

Xiaoli Zhu *

College of Economics and Management

\author{
Yunnan Agricultural University \\ Kunming, China \\ lily7277@163.com
}

Hao Yin

International Business School

Yunnan University of Finance and Economics

Kunming, China

yinhaoli@163.com

\begin{abstract}
Agricultural cooperation between China and Timor-Leste is not only a need for China's overall diplomacy, but also an inevitable requirement for the sustainable development of agriculture and the development of agricultural enterprises. In recent years, the agricultural cooperation between China and Timor-Leste has been deepening. The cooperation fields have covered all aspects of assistance, trade and investment. It is presenting a good trend of development. However, some problems have also been exposed in practice. China and Timor-Leste are highly complementary to each other, with great potential for cooperation and broad prospects for development. The cooperation need to deepen from multiple levels of government and enterprise by taking effective measures, make the cooperation in agricultural science and technology innovation as the main line, based on the optimization of agricultural structure between the two countries. To promote agriculture cooperation structure from primary agricultural trade to scientific and technological cooperation,. At the same time, government should improve the incentives and constraints on the supervision, financial and other related systems of investment and cooperation projects.
\end{abstract}

Keywords-agricultural cooperation; current situation; prospect outlook

\section{INTRODUCTION}

The implementation of the Belt and Road Initiative can solve the domestic overcapacity, and promote Chinese economic development. On the other hand, we can make overall use of domestic and foreign resources and markets, which is conducive to the utilization of foreign resources and the development of overseas markets. Agricultural external cooperation occupies an important position in this initiative. It is more important to promote the development and "going out" of Chinese agriculture, by make full use of markets and resources both of domestic and abroad, especially under the pressure of de-stocking.

Timor-Leste is one of the eleven sovereign nations of Southeast Asia. The country shares a land border with Indonesia and is located $500 \mathrm{~km}$ to the northwest of the
Northern Territory of Australia, across the Timor Sea. It covers an area of about $15,000 \mathrm{Km} 2$ [1]. On 20 May 2002, the democratic republic of Timor-Leste was established, and on the same day, the China and Timor-Leste established diplomatic relations. Driven by the oil industry, the national economy has developed steadily [2]. The investment environment of Timor-Leste has the following characteristics: first, the national economy is dominated by agriculture and the economic development is backward [3]. Second, infrastructure is backward, food is not self-sufficient, and there is no industrial system and manufacturing base [3]. Third, the economic structure is relatively simple. Fourth, the market has a high degree of openness to the outside world.

The main agricultural products of Timor-Leste are corn, rice and potato, and the main economic crops include coffee, rubber and coconut. Coffee is the main export product. In Timor-Leste, around $63 \%$ of households engaged in crop production, only about $25 \%$ of all households planting rice [5], but the rice is the staple food of Timor-Leste, it is partly responsible for food insecurity. The development of animal husbandry is lagging behind, mainly due to extensive farming practices and lack of feed. In Timor-Leste, the common livestock are mainly chickens, horses, cattle, buffalo, goats, sheep and pigs, most of horses do not trade and are mainly used as vehicles [5]. Timor-Leste has abundant Marine resources, but the fisheries sector contributes little to its economic growth, that is mainly due to restrictions on fishing and storage technology.

Over the past decade, China and Timor-Leste have cooperated in rice breeding and planting, seafood production, agricultural development, corn cultivation, fishing, and other fields, and have achieved ideal results [6]. Based on the current situation of agricultural development in Timor-Leste, and the results of the agricultural cooperation between the two countries, in order to achieve the goal of mutual benefit and win-win outcome, we hope that the two countries will continue to deepen agricultural cooperation. Toward this end, China will continue to provide assistance to Timor-Leste, to help its agricultural development. On the other hand, we should

\footnotetext{
* Corresponding author
} 
promote agricultural investment cooperation between the two countries, and establish a sound framework for agricultural cooperation.

\section{CURRENT SituATION AND CHARACTERISTICS OF Agricultural COOPERATION}

Over the years, the governments of China and Timor-Leste have attached great importance to the exchange and cooperation in the agricultural field, and have achieved very good results [7]. In particular, in recent years, with the deepening of political and economic and trade relations, the agricultural cooperation between the two countries has continued to deepen, and exchanges of agricultural personnel have become more frequent. The areas of cooperation have covered agricultural assistance, agricultural product trade, agricultural investment and other aspects, a new pattern of all-round, wide-ranging, and deep-level agricultural cooperation has emerged, showing a prominent characteristics of the maturity of agricultural assistance, the rapid growth of agricultural trade, and key investment fields are outstanding.

\section{A. Agricultural Assistance is Becoming more and more Mature}

The governments of the two countries have signed a number of economic and technological cooperation agreements. China donated agricultural machinery, fishing gear, rice and other materials to Timor-Leste. China assisted in building projects such as the Presidential Palace, Ministry of Defense Building, Ministry of Foreign Affairs Building, and Training Center of the Ministry of Foreign Affairs. China provided training for over 1,000 Timor-Leste civil servants, and sent medical teams to Timor-Leste for a long time, to support the economic reconstruction of Timor-Leste. China actively participated in the work of the United Nations for aiding the Timor-Leste. Since the end of the mission from 2000 to 2012, a total of more than 300 civil police and officials have been sent to Timor-Leste, to participate in UN peacekeeping operations. At the end of 2015, three hybrid rice demonstration projects have been implemented with significant results, and are well received by local farmers. In April 2016, China and Timor-Leste completed the transformation of the demonstration project of mechanization and high-yield cultivation for the whole mechanization in Timor-Leste. The project was implemented in October, 2016. In May 2017, China and Timor-Leste exchanged notes for the completion of the project of supporting Timor-Leste Grain and Grain Processing Plants and the DTMB (Digital Terrestrial Television Transmission System) project.

\section{1) Material assistance}

One feature of Chinese assistance to Timor-Leste is the focus on people's livelihood. Of all Chinese aid to Timor-Leste, the rice donation amounted to 13610 tons. The rest include cooking oil, anti-malarial drugs, bed nets, blankets and other materials that directly improve the lives of Timor-Leste. China also pays special attention to improving Timor-Leste's own capacity for construction. In Chinese aid to Timor-Leste, agricultural machinery, agricultural tools, fishing gear, police equipment and so on occupy a considerable proportion. These devices will be the world to improve the level of the development of its agriculture and fisheries, the police equipment is beneficial to improve the ability of Timor-Leste to maintain social stability, guarantee the security and stability of the Timor-Leste.

\section{2) Human resources development cooperation}

Since the establishment of diplomatic ties between the two countries, the Chinese government has attached great importance to human resource development cooperation with Timor-Leste. Each year, Timorese officials are organized to receive training in China. To date, more than 860 East Asian officials and technicians have been sent to China, to attend various types of training and seminars, which is organized for developing countries by Chinese government. China attaches great importance to the training of Timor-Leste's talent.

\section{3) Technical assistance}

China had dispatched agricultural machinery experts to Timor-Leste, to carry out agricultural machinery maintenance training. For example, August 3, 2015, Ambassador Liu Hongyang and Minister Estany Slaw of Timor-Leste attended the opening ceremony of "the 2015 Overseas Training Course for Food Processing Technology in Timor-Leste". China began sending medical teams to Timor-Leste in 2004, to raise its medical level. Since 2008, China has sent hybrid rice experts to Timor-Leste, to promote hybrid rice technology [8]. The second phase of cooperation has been successful and the third phase of cooperation is currently under way. In particular, Longping Hi-Tech Co., Ltd. took over Chinese agricultural projects in foreign aid in January 2008. At the end of 2015, it has accumulatively trained more than 500 person-times of agricultural talents for Timor-Leste, and helped the trainees and local farmers greatly increase their grain area output.

\section{B. Rapid Growth of Agricultural Trade}

Compared with the United States, Australia, Japan and other countries, the value of Chinese agricultural trade with Timor-Leste is small, and agricultural trade is not very close. China mainly imports coffee, bananas and pineapples from Timor-Leste and exports beans, grains, cigarettes, seasonings, vegetables and fruits to the Timor-Leste. Agricultural product trade of China and Timor-Leste was started in 2003, Macau S.A.R imported $\$ 3000$ worth of pineapple, Chinese agricultural exports to the Timor-Leste began in 2004, China exported $\$ 122000$ worth of beans. Subsequently, agricultural trade exchanges between China and Timor-Leste gradually increased. Fig.1. shows the agricultural trade flows between China and Timor-Leste, including product types and values.

\section{Prominent Investment Areas}

Chinese agricultural investment in Timor-Leste is mainly rice cultivation, coffee variety improvement and postpartum processing.

At the 2014 China (Hunan province) and Timor-Leste investment cooperation symposium, China and Timor-Leste signed the agreement on cooperation and development of Timor-Leste agricultural industrial park. The parties to the agreement were Longping Hi-tech, Shandong Foreign Economic Relations and East Timor Agriculture and Fisheries Department, which mainly engaged in food production, cash 
crops, livestock husbandry, fishery development, and deep processing of agricultural products. The project amounted to 50 million U.S. dollars.

On September 29, 2017, the "Timor-Leste in 2017 coffee variety improvement and postpartum processing technology overseas training course" graduation ceremony was held in Timor-Leste moxa mela area, which sponsored by the ministry of commerce of China, undertook by Yuan Longping High-Tech Agriculture company. Chinese experts have taught students from Timor-Leste about the cultivation of coffee, improved varieties, and postpartum processing techniques. And the teaching methods are diverse, including classroom lectures, group discussion, and practice investigation.

\section{Problems in Agricultural CoOPERAtion}

Through the analysis of relevant economic data, it was found that the main economic problems of the relationship between China and Timor-Leste are:

\section{A. Trade Links are not Tight Enough}

Although the economic development of Timor-Leste was on the right track from 2009, Timor-Leste's economic ties with other countries in the world have become closer. However, the economic ties between Timor-Leste and China are not very close. China has implemented the policy of exempting product tariffs and quotas for Timor-Leste's products, but the volume of trade between the two countries has shown significant fluctuations in recent years, and has not risen steadily. In addition, according to the foreign trade data of the Timor-Leste country, at the 2014, the top five trade importing countries were Portugal, Indonesia, Singapore, China, etc.; the top ten exporting countries/regions of Timor-Leste were Germany, Japan, Portugal, and United States, South Korea, Belgium, Spain, Australia, Taiwan China, and Hong Kong S.A.R.

\section{B. The Investment Business is not Positive Enough}

According to the 2015 World Investment Report issued by UNCTAD (United Nations Conference on Trade and Development), as of 2014, Timor-Leste's stock of foreign

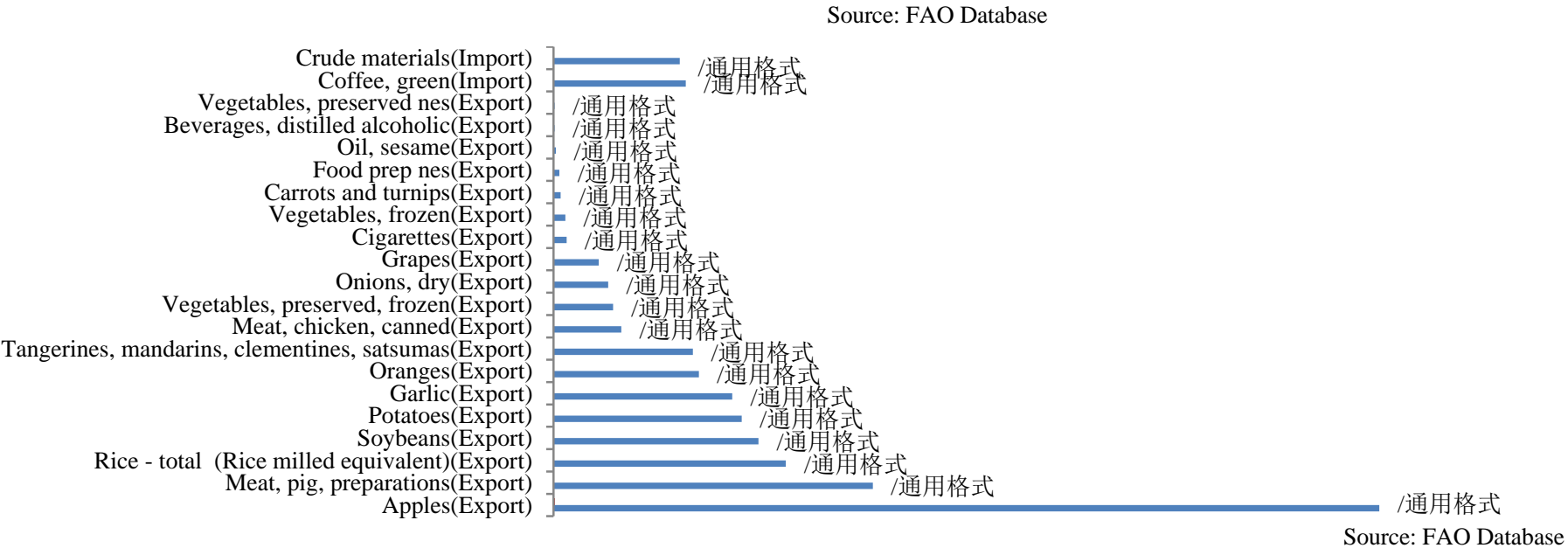

Fig.1. China and Timor-Leste Agricultural Trade in 2013 (1000 Us\$)

capital is US\$320 million. Its main investors are Singapore, Thailand, Portugal, Australia, New Zealand, the United Kingdom, South Korea and the United States. During the same period, China's total investment was only 15.78 million US dollars, accounting for only $4.9 \%$.

\section{Agricultural Assistance Lacks Ideas and Mechanism Innovation}

There are many agricultural assistance projects in Timor-Leste, but the results are not satisfactory. The biggest problem is the lack of effective knowledge accumulation mechanisms, to promote agricultural cooperation between China and Timor-Leste. This is mainly caused by the following reasons.

First, there is a lack of national-level master planning and policy coordination. This leads companies to be unfamiliar with national policies, which result in unreasonable layout of agricultural assistance projects.

Second, there is a lack of innovation in aid methods. Currently, it is basically still stuck in traditional aid methods, such as past training of agricultural personnel, sending agricultural technical experts, establishing agricultural technology demonstration centers, and lacking innovations that combine aid and development.

Third, the country's agricultural infrastructure in Timor-Leste is weak, economic growth is slow, the macroeconomic environment is also unstable, and risks are very high. 
TABLE I ECONOMIC ASSISTANCE TO TIMOR-LESTE BY MAJOR COUNTRIES

\begin{tabular}{|c|c|c|}
\hline countries & Assistance amount (\$100 million) & Ranking \\
\hline Australia & 5.65 & 1 \\
\hline The United States & 1.58 & 2 \\
\hline The European Union & 1.49 & 3 \\
\hline Japan & 0.85 & 4 \\
\hline
\end{tabular}

Source: Foreign Investment Cooperation Country (Region) Guide — Timor-Leste (2015 edition)

\section{Information Services Provided by Government \\ Departments are Seriously Inadequate}

Timely and accurate information is very important for successful agricultural cooperation. It is also very urgent. Looking at international experience, many countries have played an irreplaceable role in collecting, analyzing, and releasing information, when conducting external agricultural cooperation. For example, the United States has agricultural counselors at many embassies abroad, providing a large amount of reliable agricultural information for its domestic government departments and related companies. The Chinese government apparently lags behind in this respect. Due to poor information, many Chinese companies cannot obtain timely information on the host country's projects and relevant regulations and policies.

\section{DEVElopment PRospeCtS AND COUNTERMEASURES OF AGRICULTURAL COOPERATION}

\section{A. Development Prospect}

Since the establishment of diplomatic ties between China and Timor-Leste in May 2002, bilateral relations have been developing smoothly. In 2015, the volume of trade in the Middle East topped 100 million U.S. dollars for the first time, reaching 110 million U.S. dollars, a year-on-year increase of $76.5 \%$. Thereinto, China's exports to Timor-Leste were US\$106 million, and imports were US\$1 million, which was a year-on-year increase of $75.6 \%$ and $62.6 \%$ respectively. In 2015, China was Timor-Leste's third largest trading partner, after Indonesia and Singapore. At present, there are 11 large state-owned enterprises registered in Timor-Leste, and a large number of private enterprises in Timor-Leste carry out engineering, real estate, trade and agricultural development in Timor-Leste. There are also thousands of individual Chinese operators engaged in labor, construction, trade, catering and other industries in Timor-Leste. In Timor-Leste, Chinese state-owned enterprises are mainly engaged in engineering projects, and there are enterprises trying to invest in agriculture. With the economic development of Timor-Leste gradually getting out of the way, Chinese investment in Timor-Leste investment and business enterprises and individuals are increasing, and the competitive price competition among bidding companies is becoming increasingly fierce.

Overall, Timor-Leste is a young country with weak infrastructure, and the country is in a state of unrequited development. Since the fifth government took office, although efforts have been expedited to establish and improve the administrative structure, clarify institutional settings and functions, problems are still prominent, such as loose management, lack of effective management, lack of talents, low administrative efficiency, and weak enforcement. The effectiveness of the governance of the sixth government since it took office has not significantly improved. Timor-Leste has a biggish oil revenue reserve, and along with the implementation of the national medium- and long-term development plan, the economy of Timor-Leste will usher in a period of rapid development. It means that there will be a large demand for project construction. In order to develop the economy, Timor-Leste government and international organizations have provided much financial support. And many countries, including China, Australia, Japan, New Zealand and the European Union, are exempt from tariff treatment for the products of Timor-Leste. All these advantages will create good opportunities for Chinese enterprises and individuals to invest in Timor-Leste.

\section{B. Countermeasures and Suggestions}

\section{1) Strengthen legal coordination}

It can be improved from the following aspects. First, improve the system of jurisdiction, such as the establishment of exclusive jurisdiction system, and increase the settlement mechanism of disputes between investors and host countries. Second, establish a thorough consultation system. Third, establish a sound legal relief system. Fourth, establish a permanent dispute settlement body. With the deepening of the cooperation between China and Timor-Leste and the increasing consensus, the two countries can establish, develop and gradually improve the legally oriented judicial or quasi-judicial dispute settlement mechanism, providing legal aspects for the long-term stable cooperation between China and Timor-Leste.

\section{2) Strengthen and improve agricultural assistance to} Timor-Leste

Timor-Leste needs Chinese economic assistance to develop its economy and improve people's livelihood. Thanks to the mutual benefit, complementarity of resources and industries, the bilateral relations are getting closer. In order to promote the effectiveness of agricultural cooperation between China and Timor-Leste, China should expand the space for agricultural technical assistance, use Chinese agricultural machinery, agricultural technology and human resources to adapt to the needs of the Timor-Leste's agricultural environment, and promote its agricultural production. Chinese government should strengthen exchanges with scientific and technical personnel, actively participate in the Timor-Leste's agricultural planning work, provide scholars and opportunities for technical personnel to exchanges and study in China, carry out agricultural management and technical training, and promote the enthusiasm of East Timorese farmers for production.

\section{3) Optimize the export structure of agricultural products}

The agricultural product processing industry is the core link and important carrier for the construction of modern agriculture and agricultural industrialization. At present, there is a big gap between Chinese agricultural product processing industry and developed countries. The agricultural cooperation between China and Timor-Leste is still mainly based on the cooperative development of primary agricultural products and agricultural resources. The agricultural products trade between the two sides is mainly based on low-value-added primary 
agricultural products. With the development of agricultural technology and economy, the agricultural trade structure between China and Timor-Leste will also escalate. China can make efforts in various aspects to optimize the export structure of agricultural products, and improve the processing capacity of agricultural products in China. First, the Chinese government can actively construct a platform for the cooperation of agricultural products processing, and provide subsidies for agricultural enterprises that process and sell agricultural products, and encourage these enterprises to actively participate in international exhibitions, trade fairs and so on. The second is to cultivate a batch of leading enterprises in the export of agricultural products processing industry, and support some leading enterprises with broad market prospects and large development potential through funds and projects. Third, China should further improve the service system of the agricultural products processing industry, establish a sound information service system for the agricultural product processing industry, and timely provide relevant agricultural enterprises with industry development trends, advanced production technologies, and management models. The fourth is the application of high technology and the transformation of traditional agricultural products processing industry. China has great potential for deep processing of agricultural products. China should develop some deep processing industries with comparative advantages, speed up the transformation of scientific and technological achievements, and increase the added value of agricultural products, so as to improve the competitiveness of Chinese agricultural products in the international market.

\section{4) Strengthen agricultural technology cooperation}

Science and technology are the primary productive forces. Only by improving the level of agricultural science and technology can we fundamentally improve the conditions for agricultural production in order to get rid of the backwardness of agricultural development. The Chinese government has always devoted itself to the development of agriculture through science and technology. In the same way, China also attaches great importance to agricultural technology cooperation with agricultural cooperation among countries. When carrying out agricultural cooperation, China and Timor-Leste should strengthen communication and communication in agricultural technology through various forms. In general, China is superior to the Timor-Leste in terms of agricultural technology. China has comparative advantages in planting techniques, breeding techniques, and prevention and control of animal diseases. China and Timor-Leste can cooperate in the following agricultural technologies and make progress together.

\section{5) Strengthening the sharing of agricultural information} resources

The governments of the two countries should continue to promote the sharing of agricultural policies, resources, and market information, and keep abreast of the dynamic information and prices of the agricultural products market of the other country and the world. This will greatly increase the competitiveness of Chinese and Timor-Leste's agricultural products in the international market. There are three specific suggestions.
First, China should make full use of the advantages of the Internet, to strengthen the exchange of agricultural information between China and Timor-Leste, strengthen the construction of agricultural information websites, and strengthen the interconnection of China's agricultural information network with Timor-Leste. The establishment of network information platform can promote the spread of information about agricultural development, agricultural demand, and policies and regulations. It is possible to publish activities on training, cooperation and demonstration, and agricultural technology exchange on the Internet. It is possible to complete the registration of seminars and training courses on the Internet, improve the speed and efficiency of information communication and exchange.

Second, the agricultural institutions of the two countries should change their traditional views, which centered on their own literature and data and databases. China and Timor-Leste must work together to establish a large-scale agricultural information database with complete information, wide coverage, and universal compatibility.

Finally, based on demand and market orientation, a practical and effective information base should be established. The information base for the construction should provide services for agricultural enterprises, and provide enterprises with valuable and up-to-date agricultural information, so as to continuously improve the enthusiasm of agricultural enterprises for the development and utilization of resources. At present, China's agricultural enterprises lack information on agricultural policies, science and technology, and agricultural products from various countries in Timor-Leste. Therefore, China and Timor-Leste should work together to establish the agriculture database, to provide information for enterprises and individuals in both country. The database may include information such as national agricultural policy, agricultural supply and demand, agricultural science and technology, and so on.

\section{CONCLUSION}

Over the past decade, China and Timor-Leste have development cooperation in rice breeding and planting, seafood breeding, agricultural development, corn, fishing, and other fields, and have achieved ideal results. Based on the current situation of agricultural development in Timor-Leste and the results of bilateral agricultural cooperation, it is hoped that the two countries will continue to deepen agricultural cooperation to achieve the goal of mutual benefit and win-win results. To this end, on the one hand, China should continue to provide agricultural assistance to Timor-Leste, to help Timor-Leste develop agriculture rapidly, on the other hand, the two governments should promote agricultural investment cooperation between countries and establish a sound framework for agricultural cooperation.

\section{ACKNOWLEDGEMENTS}

We would like to express our sincere gratitude to Department of Commerce of Yunnan Province in China, for providing research fund. We also want to thanks the anonymous reviewers for their comments. 


\section{REFERENCES}

[1] Benavente Bruno. Timor-Leste Agriculture Market Systems Analysis Consultancy Report[R].USAID/Timor-Leste, pp.4-11, 2015

[2] East asia \& pacific region sustainable development department, World-Bank. Timor-Leste: Country Environmental Analysis [R], pp.25-40, 2009.

[3] The minister of finance Timor-Leste. Timor-Leste in Figures, pp.14-32, 2016 [R]. Dili, Timor Leste: Sylvia Dili, 2016.

[4] Food and Agriculture Organization of the United Nations. Regional Fisheries Livelihoods Programme for South and Southeast Asia(RFLP): Community-based data gathering and co-management of marine resources in Timor-Leste[R], pp.5-13, 2013.

[5] Food and Agriculture Organization of the United Nations. Country Programming Framework (CPF) 2015 - 2018[R]. 2014.

[6] M.A. Aksoy, and J.C. Beghin, Global Agricultural Trade and Developing Countries, The International Bank for Reconstruction and Development / The World Bank, Washington DC, 2005.

[7] Timor-leste General-Director-of-Statistics. External Trade Statistics Annual Reports 2016[Z]. 2017. http://www.statistics.gov.tl/wp-content /uploads/2017/11/Trade-Statistics-2016-Revised.pdf

[8] Leonito soares de jesus Abraão-Ribeiro-Mendonça. Government Support A Sustainalbe Development Of Rice Production In Timor-Leste [D]. University of Nordland, pp.11-24, 2015. 